\title{
Effects of Seat-Back Angle and Accelerometer Height at the Seat-Back on Seat-Back $X$ Axis r.m.s. Acceleration in Filed Experiments according to The ISO2631-1 Standard
}

\author{
Yumi NAKASHIMA ${ }^{1 *}$ and Setsuo MAEDA ${ }^{2}$ \\ ${ }^{1}$ Vehicle Research Department, ISUZU Advanced Engineering Center Ltd, 8 Tsuchidana, Fujisawa, Kanagawa, \\ 252-8501, Japan \\ ${ }^{2}$ Department of Human Engineering, National Institute of Industrial Health, 6-21-1 Nagao, Tama-Ku, Kawasaki, \\ 214-8585, Japan
}

Received March 24, 2003 and accepted November 12, 2003

\begin{abstract}
The effects of seat-back angle and accelerometer height at the seat-back on seat-back $x$ axis frequency-weighted root-mean-square (r.m.s.) acceleration have been investigated in field experiments. Experiment 1 investigated the range and variability, of frequency-weighted r.m.s. acceleration at the same measurement position, where the seat-back angle was 24 degrees from vertical on the floor and the accelerometer height was $38 \mathrm{~cm}$ up from the seat cushion surface. Experiment 2 investigated ranges of frequency-weighted r.m.s. acceleration between the reference position, which was the position used in experiment 1 , and test positions at different seat-back angles, 4 degrees ahead of and 4 degrees behind the reference position. Experiment 3 investigated the range of frequency-weighted r.m.s. acceleration between the reference position which was the same as in experiments 1 and experiment 2 , and test positions at different accelerometer heights at the seatback from a seat cushion surface, $2.5 \mathrm{~cm}$ higher, $2.5 \mathrm{~cm}$ lower and $5 \mathrm{~cm}$ lower than the reference position. This investigation clarifies that different seat-back angles and accelerometer heights at the seat-back affect the frequency-weighted r.m.s. acceleration at these measurement positions, which is beyond the exposure values at which people are able to distinguish different vibration acceleration magnitudes.
\end{abstract}

Key words: Whole-body vibration, Frequency-weighted r.m.s. acceleration, Measurement position, Seatback angle, Accelerometer height, Seat-back

\section{Introduction}

The purpose of this paper is to clarify the effects of seatback angle and accelerometer height at the seat-back from a seat cushion surface on the seat-back x-axis (fore-and-aft directions) frequency-weighted root-mean-square (r.m.s.) acceleration, to evaluate seated whole body vibration in field experiments, according to the vibration evaluation method

\footnotetext{
*To whom correspondence should be addressed.
}

specified in ISO2631-1 ${ }^{1)}$ standard.

The European parliament and the council of the European Union issued "DIRECTIVE 2002/44/EC OF THE EUROPEAN PARLIAMENT AND OF THE COUNCIL OF 25 June 2002 " 2 . It states that "the member states shall bring into force the law, regulation and administrative provisions necessary to comply with this Directive no later than 6 July 2005, in the EU". This directive requires ISO2631-1 for the assessment of vibration exposure values. "The daily exposure limit values standardized to an eight-hour reference 
period shall be $1.15 \mathrm{~m} / \mathrm{s}^{2}$ or, at the discretion of the member state concerned, a vibration dose value of $21 \mathrm{~m} / \mathrm{s}^{1.75}$ ". These values have become a point of focus since passage of the Directive gave it the force of law. Therefore, the measurement method to earn these values should be, consistently, the exact same method, to earn the same assessment values under the same measurement conditions.

There will be concern that fair assessments should be done and necessarily be consistent for assessors, measurers and workers, especially for recognition of workers' whole body vibration exposure in work environments, as required by the values in DIRECTIVE 2002/44/EU. For a fair assessment, measurement values should remain consistent. When following the required method, with the same measurement conditions, even if the measurers and the date that measurement is performed are different, there should not be extreme differences among measurers.

In ISO2631-1 that is required to earn the values "The measurement point shall be located so as to indicate the vibration at the interface between the human body and the source of vibrations, then the data taken that point shall be regarded as the frequency-weighted r.m.s. acceleration. Definitions present three principal areas for seated persons: the supporting seat surface (6 direction rectilinear vibration, $\mathrm{x}, \mathrm{y}, \mathrm{z}$ axes, and rotational vibration, pitch, yaw and roll), the seat-back ( 3 direction rectilinear vibration, $\mathrm{x}, \mathrm{y}, \mathrm{z}$ axes), and at the feet (3 direction rectilinear vibration, $\mathrm{x}, \mathrm{y}, \mathrm{z}$ axes), as these principal areas may not always be self-evident. Measurements at the supporting seat surface should be made beneath the ischial tuberosities. Measurements on the seatback should be made in the area of principal support of the body. Measurements at the feet should be made on the surface on which the feet are most often supported. In all cases the location of measurement shall be fully reported. As directions of measurement, vibration shall be measured according to a coordinate system originating at a point from which vibration is considered to enter the human body. For a person seated on an inclined seat, the relevant orientation should be determined by the axes of the body, and the z-axis will not necessarily be vertical. The orientation of the basicentric axes to the gravitational field should be noted." ISO26311 has no requirements to show the exact measurement points, axes, and no description about the effects of different measurement positions.

As to the effects of measurement positions at a seat on the weighted r.m.s. vibration acceleration, for example, there was concern about the causes of the different measurement positions at the seat cushion "angles of seat cushion surface" and "seat accelerometer positions at the seat cushion surface".
But the "angles of seats cushion surface" depend on seat designs, and "seat accelerometer positions at the seat cushion surface" did not differ greatly at the seat cushion, as the position under the ischial tuberosities was determined with a seat-pad including an accelerometer whose size was more than the $200 \mathrm{~mm}$ as described in ISO10326-13). On the other hand, it was not clarified what the effects of accelerometer positions at the seat-back on the frequency-weighted r.m.s. acceleration might be. Selections at "seat-back angles" and "accelerometer heights at the seat-back from a seat cushion surface" are larger than a seat cushion. It was not yet clarified the effects of those different measurement positions on the frequency-weighted r.m.s. acceleration might be in view of the preference for different measurement points at the seatback to ones at a seat cushion.

Kato et al. ${ }^{4)}$ investigated the equivalent comfort contours for vibrations in sitting postures, seat-back angles including seat cushion angles, vertical, 20 and 40 degrees from vertical, with sinusoidal and random vibration exposure for the effects of different measurement positions at the seat-back, on measurement values. It shows the comparison of equivalent comfort contours at the seat-back $\mathrm{x}$ axis from 1 to $100 \mathrm{~Hz}$ with different postures. As a result, it clarifies that equivalent comfort contours of the seat-back angle 20 degrees from vertical are similar to those of the seat-back angle 40 degrees from vertical, and not with those of a vertical seat-back. This paper also reports the frequency-weighted r.m.s. acceleration measured at exposed random vibration. But it does not describe the exact measurement position.

Corbridge et al..$^{5}$ investigated that the effects of the seatback angles 95, 105, 115 degrees from horizontal place at the measurement points which are the seat surface and seat floor with the random vibration $0.5-25 \mathrm{~Hz}$, to the transmissibility between a floor and a seat cushion. This investigation clarifies the effect of seat-back angle on the transmissibility between a floor and a seat cushion, but it does not describe the frequency-weighted r.m.s. acceleration.

Lewis et al. $\left.{ }^{6}\right)$ investigated the frequency-weighted r.m.s. acceleration of nine different transportation systems with a method according to ISO2631-1, but it does not describe exact measurement positions for accelerometers on seats at each evaluation.

There are studies on frequency-weighted r.m.s. acceleration measured on seat cushions and seat-backs by Paddan ${ }^{7)}$ and Griffin $^{8)}$, but they do not describe exact measurement positions but only that it was measured at the seat cushions and the seat-backs. Therefore, there are no previous reports to refer to on the effects of "seat-back angle" and "accelerometer height at the seat-back from a seat cushion 
surface" on the seat-back x-axis frequency-weighted r.m.s. acceleration.

There are three experiments, experiment 1 , experiment 2 and experiment 3 , which are field experiments on measuring a driver's vibration exposure while a drives along a concrete road which causes a constant vibration magnitude input in this paper. These experiments were performed to examine the effects of different measurement positions at the seatback on the seat-back x-axis frequency-weighted r.m.s. acceleration, which is one of the major measurement points affecting comfort reported by Kato et al. ${ }^{4)}$ and to be encouraged at ISO2631-1 for evaluation of health, and since the consideration of a consistent and equitable assessment is necessary when taking measurements of whole body vibration in work environments. In experiment 1 , ranges of the frequency-weighted r.m.s. acceleration measured at the same measurement position that had the seat-back angle 24 degrees from a vertical and the accelerometer height at the seat-back $38 \mathrm{~cm}$ above the seat cushion surface, as the reference data, were investigated to judge the effects of different measurement positions. In experiment 2 the ranges of the frequency-weighted r.m.s. acceleration between seatback angles \pm 4 degrees from the reference position and the reference position which was same as in experiment 1 were investigated. In experiment 3 , ranges of the frequencyweighted r.m.s. acceleration between three different accelerometer heights at the seat-back from a seat cushion surface, $2.5 \mathrm{~cm}$ higher, $2.5 \mathrm{~cm}$ lower, and $5 \mathrm{~cm}$ lower than the reference position, and the reference position which was $38 \mathrm{~cm}$ above the seat cushion surface were investigated. Then it was concluded the effect of different measurement positions from all results of each experiment was due to the reference position.

\section{Experiment}

\section{Experiment 1}

Aims: The aim of experiment 1 was the investigation of the range of the seat-back $\mathrm{x}$-axis (fore and back directions) frequency-weighted r.m.s. acceleration in field experiments which repeated measurements of driver's vibration exposure when a driver drove the same car on the same road. This result would be referenced to experiment 2 and experiment 3 to judge the difference in measurement conditions or errors.

Apparatus: The purpose of this study is to clarify the effects of seat-back angles and accelerometer heights on seat-back x-axis frequency-weighted r.m.s. acceleration. There have been several reports that show how body characteristics influence the measurement values of seated

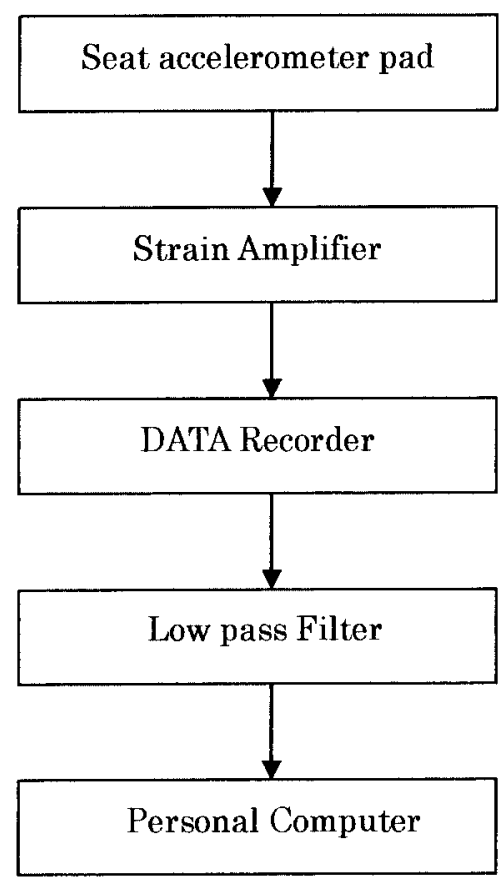

Fig. 1. Block diagram of measuring apparatus.

subjects according to Griffin et al. ${ }^{9)}$, Corbridge et al. ${ }^{5)}$ and Fairley et al. ${ }^{10)}$. On the other hand, universality was reported by Parson et al. ${ }^{11)}$ whose experiment was designed with a single seated subject for the 12 axes measurement in a field experiment for the reference data. Therefore, this experiment was designed for a single subject driver to exclude the effects of the subject's body characteristics. A one axis seat accelerometer pad, 1-axis Entran EGCS-DO*-10V, according to ISO5008 ${ }^{12)}$ specifications, was located in a Sports Utility Vehicle driver's seat-back. In this study, the measurement direction was determined by the axes of the seated body according to the ISO2631-1 as the seat pad was located on the seat-back surface. The center of the seat accelerometer pad was located $38 \mathrm{~cm}$ up from the seat cushion surface. Signals from the seat accelerometer pad were amplified by a KYOWA strain Amplifier DPM-12A and recorded with a TEAC RD180T PCM DATA Recorder. The data length was $5.5 \mathrm{~min}$. Recorded signal data were converted to a personal computer with a sampling frequency of $100 \mathrm{~Hz}$ and a hanning window, passing through a $40 \mathrm{~Hz}$ low pass filter which was an NF Electronic Instruments MS-525 $48 \mathrm{~dB}$ /oct Filter, as Fig. 1 shows.

Experimental Method: The position where the subject driver, a 40-year-old, $80 \mathrm{~kg}, 1.65 \mathrm{~m}$ tall male sat was on a Sports Utility Vehicle driver seat, which had a seat accelerometer pad, including an accelerometer, on the seatback and which was decided to be the most comfortable 
driving position by the driver, and was the reference position. The reference position was a seat-back angle 24 degrees from a position vertical to the vehicle floor and the accelerometer height was $38 \mathrm{~cm}$ from the seat cushion surface; fitted between the subject driver's back and the seatback, just below the subject driver's shoulder blades. Fig. 2 shows the reference position.

The subject driver was urged to drive the car at the same speed, $40 \mathrm{~km} / \mathrm{h}$, on the same concrete road that created regular random vibration without a seatbelt, after deciding the driving position. Measurements were started at the time the car speed was fixed at $40 \mathrm{~km} / \mathrm{h}$ and continued until $5.5 \mathrm{~min}$ of continuous driving data were taken. There were $3 \mathrm{~min}$ of rest time, when the subject driver got out of the Sports Utility Vehicle, between each 5.5 min measurement at the reference position. These flows were done 3 times in experiment 1 . The number of measurements was referred to the Report Form of ISO5007 $7^{13)}$ and ISO7096 ${ }^{14}$. All data were analyzed to earn the evaluation values following the equation after $\mathrm{Wc}$ frequency weighting for the seat-back $\mathrm{x}$-axis which was according to ISO2631-1 with MATLAB software ${ }^{15)}$.

$$
a_{w}=\left[\frac{1}{T} \int_{0}^{T} a_{w}{ }^{2}(t) d t\right]^{\frac{1}{2}}
$$

$\mathrm{a}_{\mathrm{w}}$ : the frequency weighted r.m.s. acceleration

$a_{w}(t)$ : the frequency weighted acceleration at time $t$.

$\mathrm{T}$ : the measurement duration

Results: It was found that the average of the frequencyweighted r.m.s. acceleration, which was measured three times at the same measurement position, was $0.384 \mathrm{~m} / \mathrm{s}^{2}$, and the standard deviation was $0.004 \mathrm{~m} / \mathrm{s}^{2}$ as Fig. 5 shows. The minimum difference of each value was $0.004 \mathrm{~m} / \mathrm{s}^{2}$ and the maximum difference of each value was $0.008 \mathrm{~m} / \mathrm{s}^{2}$.

There was no significant difference $(\mathrm{p}<0.1)$ in those assessment values which were within $90 \%$ confidence interval on the t-distribution by degrees of freedom in this experiment data.

\section{Experiment 2}

Aims: The aim of experiment 2 was the reconfirmation of the seat-back x-axis frequency-weighted r.m.s. acceleration earned in experiment 1 , repeatability, and confirmation of the difference in the frequency-weighted r.m.s. acceleration at different seat-back angles from the reference position, i.e. the measurement position in experiment 1 , which is 4 degrees ahead of the reference position and 4 degrees behind the reference position which might be larger or smaller than the frequency-weighted r.m.s. acceleration at the reference position.

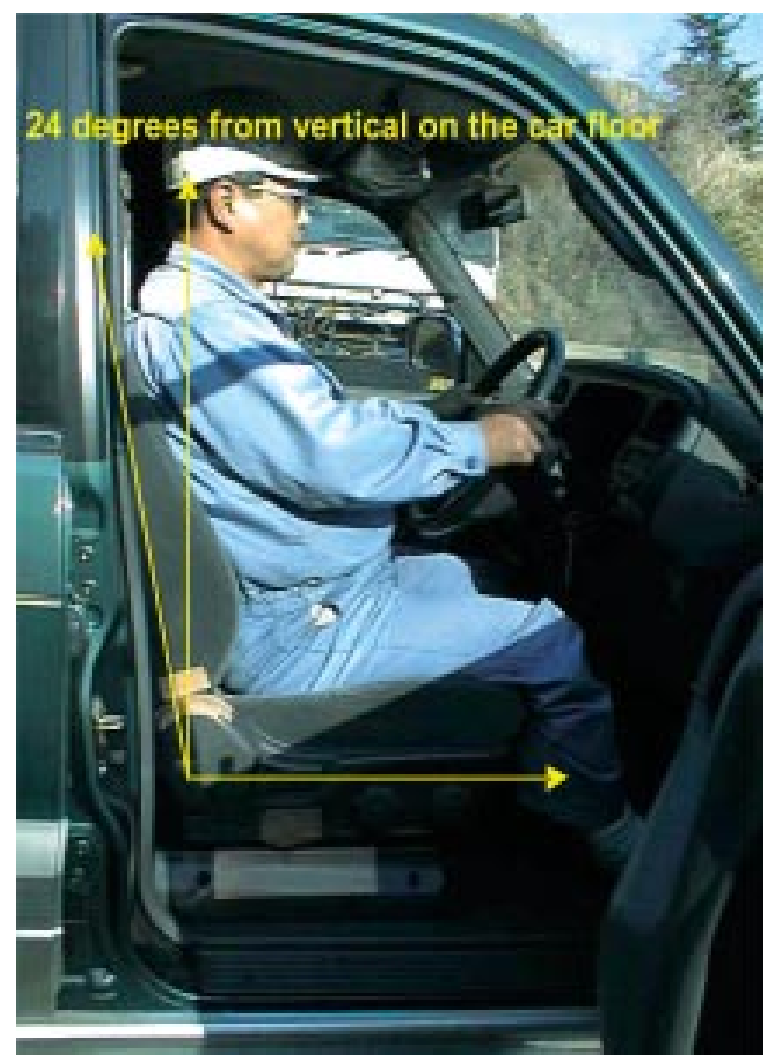

Fig. 2. Measurement position in experiment 1 , which was the reference position for experiments 2 and 3 .

The reference measurement position was the seat back angle 24 degrees from perpendicular to the vehicle floor and the accelerometer height was $38 \mathrm{~cm}$ above the seat cushion surface.

Apparatus: The measuring equipment used for experiment 2 was the same as for experiment 1.

Experimental Method: The ranges of frequency-weighted r.m.s. acceleration in the field experiment which repeated measurements of the driver's vibration exposure during the time the driver drove the same Sports Utility Vehicle on the same road were investigated. This result would be a reference for experiment 2 and experiment 3 to judge the difference in measurement conditions or errors.

The effect of seat-back angles was investigated. There were 3 positions, including the reference position. The other two positions were 4 degrees ahead and 4 degrees behind the reference position. Fig. $3 \mathrm{a}$ to Fig. $3 \mathrm{c}$ show the subject driver at the each seat-back angle. Fig. $3 b$ shows the reference position, the most comfortable position for the subject driver. It shows a suitable space between the driver's back and the seat-back. Fig. 3a shows 4 degrees behind the reference position. It shows a little more space between the driver's back and the seat-back. The driver's posture was somewhat 


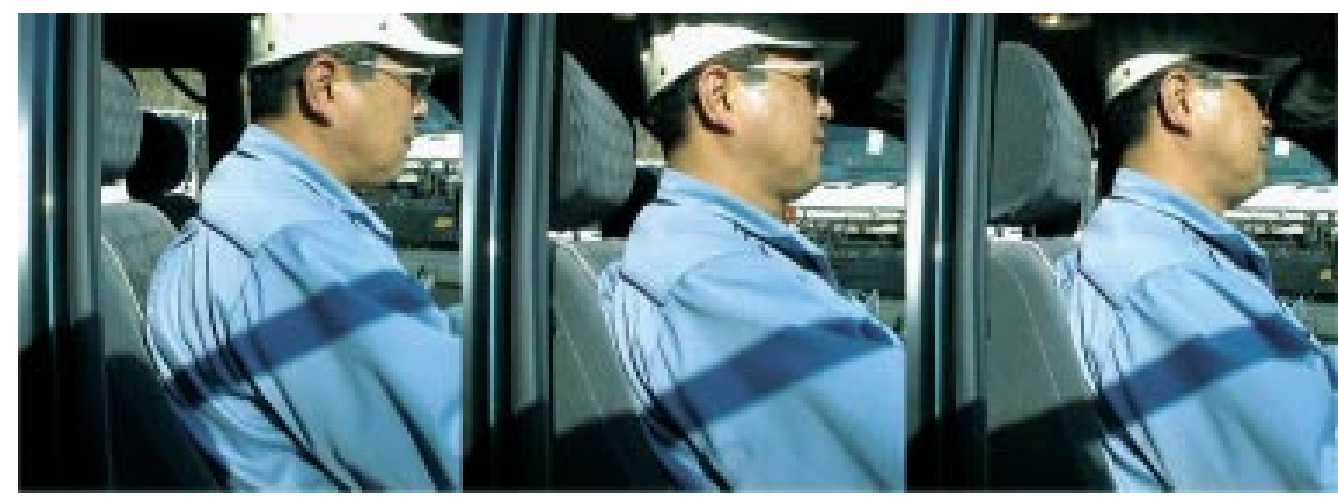

a

b

c

Fig. 3. Measurement positions of different seat-back angles in experiment 2.

a: The seat-back angle was 4 degrees behind the reference position which was the same measurement position as in experiment $1 . \mathrm{b}$ : The reference position which is the same measurement position as in experiment 1 . The reference measurement position was the seat back angle 24 degrees from perpendicular to the vehicle floor and the accelerometer height was $38 \mathrm{~cm}$ above the seat cushion surface. c: The seat-back angle was 4 degrees ahead of the reference position which is the same as the measurement position in experiment 1.

strained, and therefore, not comfortable. Fig. 3c shows 4 degrees ahead of the reference position. It shows the seatback pushed against the driver's back. Each measurement condition was measured one time and the frequency-weighted r.m.s. acceleration was calculated.

Results: The frequency-weighted r.m.s. acceleration of the reference position in this experiment was almost the same as the frequency-weighted r.m.s. acceleration in experiment $1,0.383 \mathrm{~m} / \mathrm{s}^{2}$, as this value was not greater than the standard deviation in experiment 1 . It was clarified that the frequencyweighted r.m.s. acceleration at 4 degrees back from the reference position was $0.07 \mathrm{~m} / \mathrm{s}^{2}$ different from the value at the reference position as Fig. 6 shows. On the other hand, the frequency-weighted r.m.s. acceleration at 4 degrees ahead of the reference position was only $0.01 \mathrm{~m} / \mathrm{s}^{2}$ different from the value at the reference position. These differences in values were 2.5 to 17 times greater than the standard deviation in experiment 1 . There was a significant difference $(\mathrm{p}<0.05)$ between the test positions which were different seat-back angles and the reference position which was the same as in experiment 1 , because $\mathrm{H}_{0}$ which was the null hypothesis, "ranges of these difference changing seat-back angles might be 0 " was not chosen at the statistical hypotheses testing by a t-distribution.

\section{Experiment 3}

Aims: The aim of experiment 3 was the confirmation of differences in the seat-back x-axis frequency-weighted r.m.s. acceleration at the different accelerometer heights at the seat- back from the reference position which were $2.5 \mathrm{~cm}$ higher, $2.5 \mathrm{~cm}$ lower and $5 \mathrm{~cm}$ lower than the reference position that might be larger or smaller than the frequency-weighted r.m.s. acceleration at the reference position.

Apparatus: The apparatus used for experiment 3 was the same as for experiments 1 and 2 .

Experimental Method: The same subject driver was used in experiments 1 and 2 and the seat-back was measured at different accelerometer heights, under the same conditions, driving the same Sports Utility Vehicle car on the same road at the same speed of $40 \mathrm{~km} / \mathrm{h}$, as in experiments 1 and 2 . The seat accelerometer pad was centered in the position at the center line of the seat-back which located in the area of principal support of the body, inside of the seat-back and a little higher than the subject driver's waist. It was measured at each measurement position, $2.5 \mathrm{~cm}$ higher, $2.5 \mathrm{~cm}$ lower and $5 \mathrm{~cm}$ lower than the reference position, which were satisfactory locations at the seat-back, and there was $3 \mathrm{~min}$ rest time between measurements. Each measurement was done once. Fig. 4a to Fig. 4d show the seat-pad heights at the seat-back. Measuring data were calculated as the frequency-weighted r.m.s. acceleration the same as in experiments 1 and 2.

Results: Differences in the frequency-weighted r.m.s. acceleration at 3 other different heights, $2.5 \mathrm{~cm}$ higher, 2.5 $\mathrm{cm}$ lower and $5 \mathrm{~cm}$ than the referent position were at least $0.04 \mathrm{~m} / \mathrm{s}^{2}$ smaller and $0.05 \mathrm{~m} / \mathrm{s}^{2}$ larger than the frequencyweighted r.m.s. acceleration at the reference position as Fig. 7 shows. These differences in values were 10 to 12.5 times 


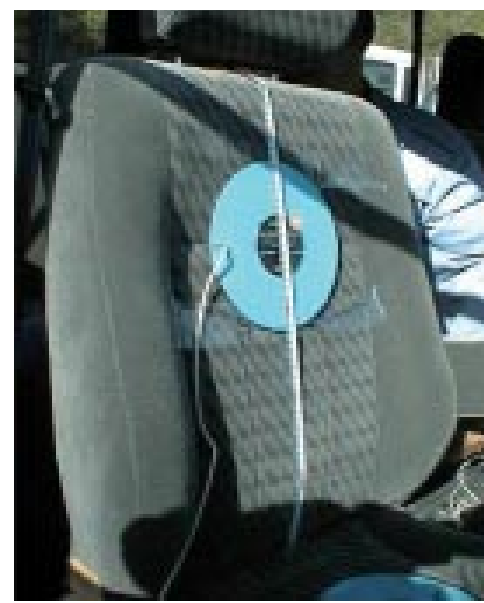

a

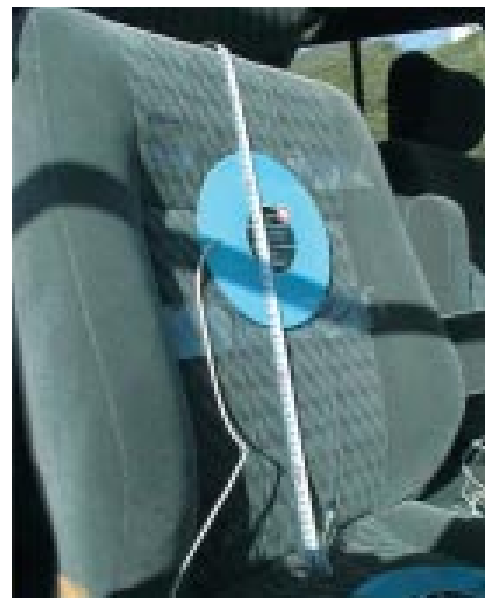

c

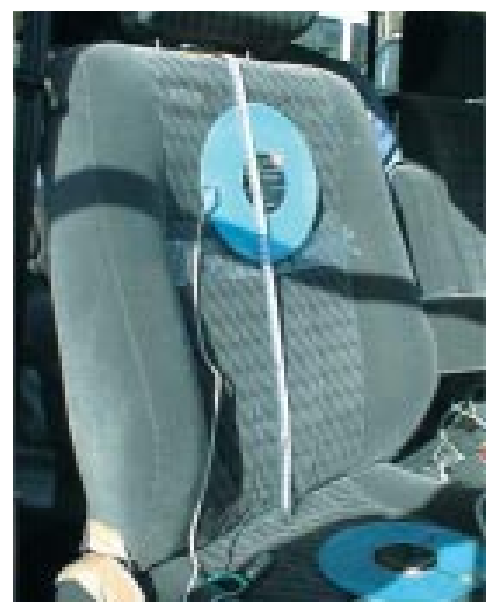

b

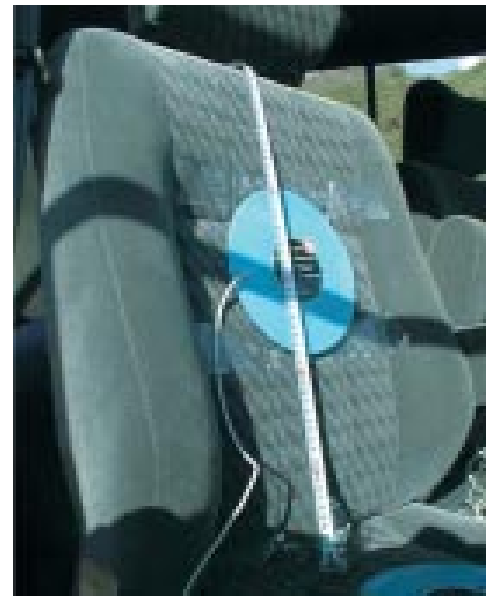

d

Fig. 4. Different accelerometer heights in experiment 3.

a: The reference position which is the same measurement position as in experiment 1 . The reference measurement position was the seat back angle 24 degrees from perpendicular to the vehicle floor and the accelerometer height was $38 \mathrm{~cm}$ above the seat cushion surface. b: The accelerometer height was $2.5 \mathrm{~cm}$ above the reference position which was the same as the measurement position in experiment 1. c: The accelerometer height was $2.5 \mathrm{~cm}$ below the reference position. d: The accelerometer height was $5 \mathrm{~cm}$ lower than the reference position.

more than the standard deviation in experiment 1 . There was a significant difference $(\mathrm{p}<0.05)$ between test positions which were for different accelerometer heights and the reference position which was the same as in experiment 1 , for the same reason for statistical hypotheses testing as in experiment 2.

\section{Discussion}

\section{Discussion of experiment 1}

The average of the seat-back $\mathrm{x}$-axis frequency-weighted r.m.s. acceleration was $0.384 \mathrm{~m} / \mathrm{s}^{2}$. This was in the category of "a little uncomfortable" on the scale of discomfort suggested in ISO2631-1. The standard deviation of 0.004 $\mathrm{m} / \mathrm{s}^{2}$ showed repeatability under the same measurement conditions and differences between measurement r.m.s. values of $0.004-0.008 \mathrm{~m} / \mathrm{s}^{2}$ were with in the category of "a little uncomfortable" and did not affect the assessment of discomfort, as Fig. 8 shows. The effect on the frequencyweighted r.m.s. acceleration from repeatable measurements was very small, it was found that the same seat-back $x$-axis frequency-weighted r.m.s. acceleration was earned even if measurements were repeated. 


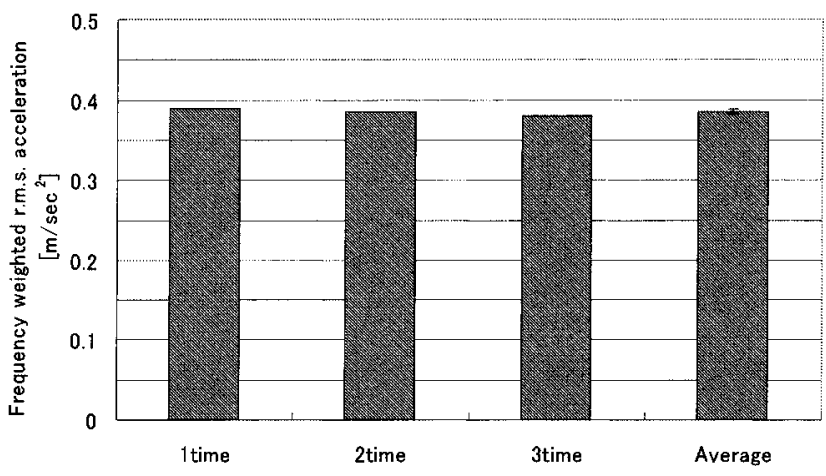

Fig. 5. Experiment 1 all of the seat-back $x$-axis frequency-weighted r.m.s. values at same measurement position.

The average frequency-weighted r.m.s. acceleration measured three times at the same measurement position was $0.384 \mathrm{~m} / \mathrm{s}^{2}$ and the standard deviation was $0.004 \mathrm{~m} / \mathrm{s}^{2}$.

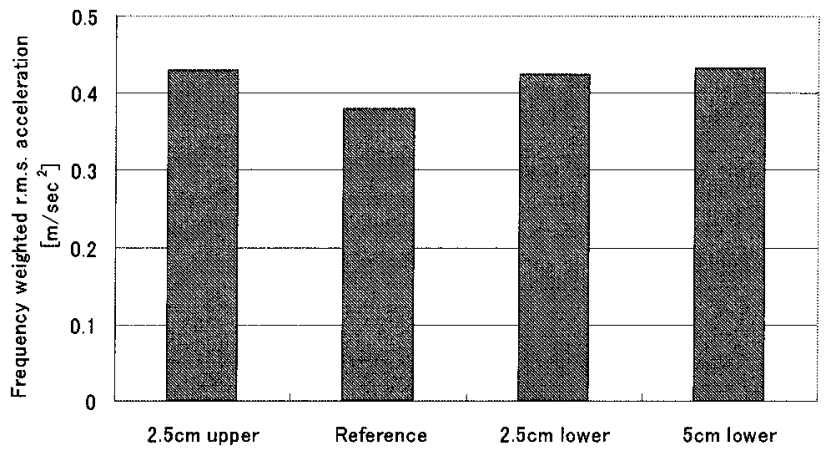

Fig. 7. Experiment 3 all of the seat-back $x$ axis frequency-weighted r.m.s. values at different accelerometer heights on the seatback surface.

The frequency-weighted r.m.s. acceleration at other 3 different heights, $2.5 \mathrm{~cm}$ above, $2.5 \mathrm{~cm}$ lower and $5 \mathrm{~cm}$ lower than the reference position were $0.04-0.05 \mathrm{~m} / \mathrm{s}^{2}$ bigger than the frequency-weighted r.m.s. acceleration at the reference position.

\section{Discussion of experiment 2}

The consistency of the frequency-weighted r.m.s. acceleration measured at the same measurement position as in experiment 1 was reconfirmed in this experiment as the difference between the evaluation value of the reference position in experiment 2 the same as in experiment 1 and the average of evaluation value in experiment 1 was less than the standard deviation in experiment 1 . There might be concern about the small difference in measurements made at the location of the accelerometer height from the seat surface because of different seat-back angles. Another possible concern could be of the fore-and-aft direction at the seat-back surface in accordance with ISO2631-1 as to the definition of the measurement $\mathrm{x}$-axis at the seat-back

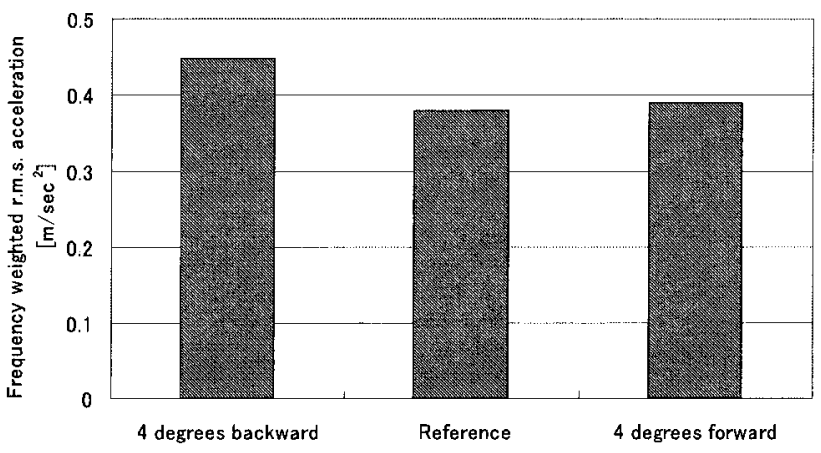

Fig. 6. Experiment 2 all of the seat-back $x$-axis frequency-weighted r.m.s. values at different seatback angles.

The frequency-weighted r.m.s. acceleration at 4 degrees behind the reference position was $0.07 \mathrm{~m} / \mathrm{s}^{2}$ different from the value at the reference position. The frequency-weighted r.m.s. acceleration at 4 degrees ahead of the reference position was only $0.01 \mathrm{~m} / \mathrm{s}^{2}$ different from the value at the reference position.

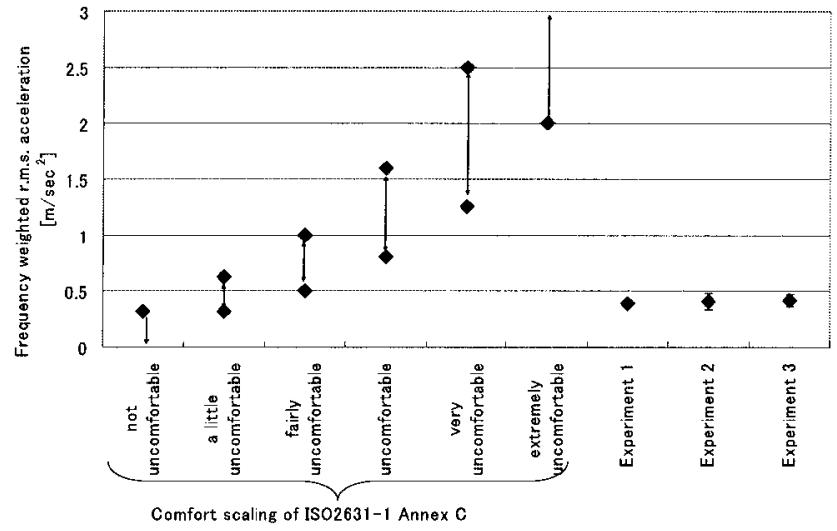

Fig. 8. Comparison between ISO2631-1 comfort scaling and averages and ranges for experiments 1,2 and 3.

The averages and ranges of assessment values in experiments 1, 2 and 3 did not affect the assessment of discomfort.

including seat-back angles. Nevertheless, this concern was not addressed in this experiment since using the seat-pad, including the accelerometer inside, falls within the specifications of ISO5008 and definition of the direction of measurement at ISO2631-1, that the relevant orientation should be determined by the axes of the body for a person seated on an inclined seat and the z-axis will not necessarily be vertical, that is 90 degrees from the $\mathrm{x}$-axis.

At differences of the frequency weighted r.m.s. acceleration on the seat-back $\mathrm{x}$ axis between the reference position and other test positions which were different seat-back angles, the difference was $0.07 \mathrm{~m} / \mathrm{s}^{2}$ larger at the seat-back angle 4 degrees back from the reference position, and another one 
was only $0.01 \mathrm{~m} / \mathrm{s}^{2}$ larger at the seat-back angle 4 degrees ahead of the reference position. It was $0.06 \mathrm{~m} / \mathrm{s}^{2}$ larger at the 4 degrees behind the reference position and 4 degrees ahead of the reference position. This shows that the frequency weighted r.m.s. acceleration at the measurement position of different seat-back angles from the reference position were larger than the one of the reference position which was the most comfortable position for the subject driver. As to the cause of this result, it is shown in Fig. 4. Pre-tests were done after these experiments. It was admitted that these effects were mainly caused by the space between the subject driver's back and the seat-back, which causes different pressure to be placed on the accelerometer because of the position of the subject driver's back and the seat-back. At first, the vibration magnitude at 4 degrees behind the reference position was larger than at the reference position because the seat accelerometer pad was moved more at the larger space between the subject driver's back and the seat-back, which causes weaker pressure to touch the accelerometer than in the reference position. Secondly, vibration magnitude at 4 degrees ahead of the reference position was larger than at the reference position, as a larger movement might be caused by the subject driver's body movements as the seat-back pushed against the subject driver's back or the smaller pressure to touch on the accelerometer than in the reference position, because the accelerometer was not fitted as well as at the reference position. This difference did not affect the assessment of discomfort as it was in the same category, though it was examined according to the scale of discomfort suggested in ISO2631-1 Annex C, as Fig. 8 shows. Nevertheless, there was a significant difference between test positions and the reference position in experiment 2 , and differences which were between each evaluation values and the average in experiment $1(\mathrm{p}<0.05$, $\mathrm{F}$ test). Therefore, attention should be paid to the measurement position at the same seat-back angles so as not to have any effect on seat-back angles, or the seat-back angles should be recorded with measurement values.

\section{Discussion of experiment 3}

Measurement positions were the different accelerometer heights at the seat-back from the reference position which were up and down positions from the reference position on the center line of the seat-back and which were not right and left positions from the reference position or the center line of the seat-back, because those positions were not admitted as the area of principal support of the body by several volunteers in the pretest.

The difference between the frequency-weighted r.m.s. acceleration measured at different accelerometer heights from the reference position and it being measured at the reference position in experiment 2, was confirmed in this experiment. Differences at different accelerometer heights were almost the same at all measurement heights, because of $0.05 \mathrm{~m} / \mathrm{s}^{2}$ between the height of $2.5 \mathrm{~cm}$ higher than the reference position and the reference position and $0.04-0.05 \mathrm{~m} / \mathrm{s}^{2}$ between the heights of $2.5 \mathrm{~cm}$ and $5 \mathrm{~cm}$ lower than the reference position and the reference position. As to the cause of this result, it was considered next. For the reference position, the seat-pad movement was minimal as there was a natural attachment between the seat-pad and subject driver's back, because of the seat design, and was located just below the subject driver's shoulder blade. For others, there were the effects of larger movement at the $2.5 \mathrm{~cm}$ upper, as the distance was farther than the reference position and at the $2.5 \mathrm{~cm}$ and $5 \mathrm{~cm}$ lower as the accelerometer itself moved because there was more space between the seat-back and subject driver's back. These differences did not affect discomfort as they were in the same category as in experiments 1 and 2, though it was examined with the scale of discomfort as suggested in ISO2631-1 Annex C, as Fig. 8 shows. However, there were significant differences between the test positions and the reference position in experiment 3 , and differences which were between each evaluation values and the average at experiment $1(p<0.05$, $\mathrm{F}$ test). Therefore, one should observe measurement conditions, and the spaces between the seat-back and subject driver's back, in order not to have unnecessary vibration.

\section{Discussion of comparison between experiments 1, 2 and 3}

The consistency of the frequency-weighted r.m.s. acceleration at the same measurement position in experiment 1 was confirmed in experiment 2 . The differences between the evaluation values and the average in experiment 1 were significantly smaller than the differences between the test positions and the reference positions in experiment 2 and experiment $3(\mathrm{p}<0.01 ; \mathrm{F}$ test). It was proved that it was possible to have the same values at the same measurement positions and conditions in which standard deviation in experiment 1 was $5.6-40 \%$ of the one in experiment 2 , and $8-10 \%$ of the one in experiment 3 . Therefore that assessment values remained consistent with measurements at the same measurement point was proven, when compared with the results at different measurement positions.

The difference in the frequency-weighted r.m.s. acceleration between 4 degrees behind the reference position and the reference position of $0.07 \mathrm{~m} / \mathrm{s}^{2}$ was larger than the difference in the frequency-weighted r.m.s. acceleration between 4 degrees ahead of the reference position and the 
reference position of $0.01 \mathrm{~m} / \mathrm{s}^{2}$. This frequency-weighted r.m.s. acceleration value at 4 degrees behind the reference position was larger than the difference in the frequencyweighted r.m.s. acceleration of $0.04-0.05 \mathrm{~m} / \mathrm{s}^{2}$ between different accelerometer heights in experiment 3.

The range of difference between seat-back angles was $0.06 \mathrm{~m} / \mathrm{s}^{2}$, whose values were 0.01 to $0.07 \mathrm{~m} / \mathrm{s}^{2}$. The range of difference between accelerometer heights was $0.01 \mathrm{~m} / \mathrm{s}^{2}$, whose values were from 0.04 to $0.05 \mathrm{~m} / \mathrm{s}^{2}$ and is smaller than others. Differences in accelerometer heights were more stable than difference in seat-back angles. It was clarified that the ranges of different seat-back angles to affect the frequency-weighted r.m.s. acceleration were larger than the ranges of different accelerometer heights.

It was examined how different those ranges felt from the ranges for humans, as it was clarified that ranges between different measurement positions in experiment 2 and in experiment 3 , were larger than the range of assessment values in experiment 1.

Mansfiled et al. ${ }^{16)}$ investigated different thresholds by using different vibration magnitudes, $0.2,0.4,0.8 \mathrm{~m} / \mathrm{s}^{2}$ which were reproductions of vertical acceleration measured at the seat guide in a small car and each signal to have the same shape as those measured at the seat guide in the car. From this investigation, humans can feel different thresholds which have vertical accelerations of the same shape. The human vibration exposure, which is the average of the frequencyweighted r.m.s. acceleration measured at the reference position in this study were almost the same value, $0.38 \mathrm{~m} /$ $\mathrm{s}^{2}$, that Mansfield et al. found, as the measurement axis was different. According to the investigation of Mansfield et $a l$. , it is possible for humans to feel the differences in vibration magnitudes, $13 \%$ of $0.4 \mathrm{~m} / \mathrm{s}^{2}$, which means humans can feel $0.055 \mathrm{~m} / \mathrm{s}^{2}$, the difference in vibration magnitudes. The maximum range, $0.07 \mathrm{~m} / \mathrm{s}^{2}$, of different seat-back angles was larger than that, the other, $0.05 \mathrm{~m} / \mathrm{s}^{2}$, of different accelerometer heights was almost the same value, compared with that of a different threshold. These ranges earned at this study were values in which it is possible to recognize differences for humans. These values were large enough to affect the different thresholds. Careful attention should be paid to the measurement positions to earn repeatable values for humans not to feel different thresholds, as it would be possible to measure the vibration magnitudes beyond different thresholds if seat-back angles or accelerometer heights on the seat-back were different.

\section{Conclusions}

The effects of seat-back angles and accelerometer heights at the seat-back on the frequency-weighted r.m.s. acceleration were studied in field experiments according to the ISO26311 .

The following results were obtained:

(1) It is possible to measure the frequency-weighted r.m.s. acceleration values, inside the range which is 0.002 $\mathrm{m} / \mathrm{s}^{2}$ in field experiments, if measurement positions and measurement conditions are exactly same.

(2) The difference in seat-back angles, \pm 4 degrees, causes the maximum range to be $0.07 \mathrm{~m} / \mathrm{s}^{2}$ for the assessment values, the frequency-weighted r.m.s. acceleration and the influence on the different thresholds.

(3) The difference in accelerometer heights at the seat-back, inside of the range, $7.5 \mathrm{~cm}$, causes the maximum range to be $0.05 \mathrm{~m} / \mathrm{s}^{2}$ for the assessment values, the frequencyweighted r.m.s. acceleration and influences the different thresholds.

(4) The specification to describe the exact accelerometer locations at the seat-back, which are seat-back angles and accelerometer heights, should be included in ISO2631-1 as the assessment method for the Wholebody vibration exposure.

\section{References}

1) International Organization for Standardization (1997) Mechanical vibration and shock-Evaluation of human exposure to whole-body vibration Part1: General requirements. ISO 2631-1.

2) Official Journal of the European Communities (2002) DIRECTIVE 2002/44/EC OF THE EUROPEAN PAELLIAMENT AND OF THE COUNCIL; 2002.

3) International Organization for Standardization (1992) Mechanical vibration - Laboratory method for evaluating vehicle seat vibration- Part1: Basic requirements. ISO10326-1.

4) Kato K, Hanai $T$ (1999) Measurement of the equivalent comfort contours for vibration in a sitting posture. InterNoise 99, 955-60.

5) Corbridge C, Griffin MJ, Harborough PR (1989) Seat dynamics and passenger comfort. Proc Instn Mech Engrs 203, 57-64.

6) Lewis CH, Griffin MJ (1998) A comparison of evaluations and assessments obtained using alternative standards for predicting the hazards of Whole-Body vibration and repeated shocks. J Sound and Vibration 
215, 915-26.

7) Paddan GS (2000) Effect of measurement period on the analysis of whole-body vibration. The 35th United Kingdom Group meeting on Human response to vibration. 329-44.

8) Griffin MJ (1990) Handbook of human vibration. Academic Press London ISBN 0-12-303040-4.

9) Griffin MJ, Whitham EM (1978) Individual variability and its effect on subjective and biodynamic response to whole-body vibration. J Sound and Vibration 58, 239-50.

10) Fairley TE, Griffin MJ (1989) The apparent mass of the seated human body: vertical vibration. J Biomechanics 22, 81-94.

11) Parson KC, Griffin MJ (1983) Methods for predicting passenger vibration discomfort. SAE 831029.

12) International Organization for Standardization (1979)
Agricultural wheeled tractors and field machineryMeasurement of whole-body vibration of the operator. ISO5008.

13) International Organization for Standardization (2003) Agricultural wheeled tractors - operator's seatLaboratory measurement of transmitted vibration. ISO5007.

14) International Organization for Standardization (2000) Earth-moving machinery-Laboratory evaluation of operator seat vibration. ISO7096.

15) The MathWorks, Inc. (1999) MATLAB software for Windows-The Language of Technical Computing Version 5.3.1.

16) Mansfield NJ, Griffin MJ (2000) Difference thresholds for automobile seat vibration. Appl Ergonomics 31, 255 61. 